\title{
Çalışanın Stres Düzeyi ile İş Performansı Arasında Bir İlişki Var mı? Eczacılık Mesleğine Yönelik Bir Literatür Taraması \\ DOI: 10.26466/opus.753945
}

\author{
Gülșen Kırpık* - Mehmet Ali Doğan ** \\ * Dr, Adıyaman Üniversitesi/Eczacılık Fakültesi, Adıyaman/Türkiye \\ E-Posta: gkirpik@adiyaman.edu.tr \\ ORCID: $0000-0003-4785-9624$ \\ ** Eczacı, Adıyaman Üniversitesi/Eczacılık Fakültesi, Adıyaman/Türkiye \\ E-Posta: mehmetalidgn14@gmail.com \\ ORCID: $\underline{0000-0002-6260-5924}$
}

Öz

Eczacllı mesleğindeki stres kavramının son yıllarda, özellikle iş yükünün artmasıyla birlikte, bilimsel çalışmaların dikkatini çekmeye başladığı söylenebilir. Stresin çalışan ve kuruluş üzerinde birçok olumlu veya olumsuz etkisi olabilir. Olumsuz etkisi olan bir stres, çalışanin enerji kaybetmesine ve hatta tükenmesine neden olabilir. Çalışanın iş performansını olumlu etkileyen stres "pozitif", iş performansını olumsuz etkileyen stres "negatif" olarak değerlendirilebilir. Bu çalışmada, eczacının ya da eczane çalışanının stres düzeyi ile iş performansı arasındaki ilişkinin belirlenmesi amactyla, ScienceDirect, Proquest ve Google Scholar online veri tabanları üzerinde bir literatür taraması yapılmıştır. Literatür taraması sonucunda, eczacılık mesleğindeki çalışanların stres düzeyi ile iş performansı arasındaki ilişkiyi doğrudan inceleyen çalışmalara rastlanılmamasına rağmen, yapılan diğer çalışma sonuçlarında eczacı ya da eczane çalışanındaki stresin iş performansını da azalttığına ilişkin ilişkileri ortaya koyan çok sınırlı sayıda çalışmaya rastlanılmış̧ır. Alan yazın incelendiğinde, eczacılık mesleğindeki çalışanların yoğun işlerinden ve beklenilen performans düzeyinden dolayı strese maruz kaldıkları ve bu durumun iş performans düzeyini de olumsuz yönde etkilediğ i belirlenmiştir. Bununla birlikte, stresin sadece iş performansı ile sınırlı kalmayıp, aynı zamanda yaptığı işten tatmin olamama, yaptı̆̆ı işe göre kazancını düşük olarak görme, çalışma saatlerini fazla görüp bunu bir yük olarak değerlendirme gibi olumsuz olarak nitelendirilebilecek algıya da yol açtı̆̆g gözlenmiştir

Anahtar Kelimeler: Stres, İş Performansı, Eczacılık Mesleğ $i$ 


\title{
Is There A Relationship Between the Employee's Stress Level and Job Performance? A Literature Scanning for the Pharmaceutical Profession
}

\begin{abstract}
It can be said that the concept of stress in the pharmacy profession has started to attract the attention of scientific studies, especially with the increasing workload. Stress can have many positive or negative effects on the employee and organization. Stress with a negative impact can cause the employee to lose energy and even be exhausted. The stress that positively affects the job performance of the employee can be evaluated as "positive" and the stress that negatively affects the job performance can be evaluated as "negative". In this study, a literature review was conducted on Science Direct, Proquest and Google Scholar online databases to determine the relationship between the stress level and job performance of the pharmacist or pharmacy worker. As a result of the literature review, although there are no studies directly examining the relationship between the stress level and job performance of the employees in the pharmacy profession, a very limited number of studies have been found in other studies that reveal the relationships that the stress in the pharmacist or pharmacy worker also reduces the job performance. When the literature is examined, it is determined that employees in the pharmacy profession are exposed to stress due to their busy work and expected performance level, and this situation negatively affects their job performance level. However, it has been observed that stress is not only limited to job performance, but also to the dissatisfaction with the work it does, to see the low earnings compared to the work it performs, to see the working hours more and evaluate it as a burden, as well as to a negative perception.
\end{abstract}

Keywords: Stress, Job Performance, Pharmacy Profession 


\section{Giriş}

Günümüzün çok karmaşık, belirsiz ve değişken yapısı tüm bireyler üzerinde olduğu gibi eczacılar ve eczane çalışanları üzerinde de baskı ve gerilime dolayısıyla strese yol açmaktadır. Özellikle küresel düzeyde yaşadığımız, ne zaman ve nasıl çözüleceğini bilemediğimiz COVID-19 pandemisiyle birlikte yaşanılan stres düzeyinin daha da yüksek olduğu söylenebilir. Ancak, çalışanların bireysel özellikleri ile demografik özellikleri ya da içinde bulunduğu kültürden kaynaklı farklılıklardan dolayı, aynı işyerinde çalışanların bazıları benzer koşullardan daha az etkilenirken bazıları ise daha fazla olumlu ya da olumsuz etkilenebilir.

Eczanelerin sahibi ve aynı zamanda mesul müdür olarak yöneticisi konumunda olan eczacılar ile eczanenin çalışanları yani personelinin de son zamanlardaki artan iş yükü (Çakır Yıldız ve Güneş, 2017; Schafheutle, Seston ve Hassell, 2011; Gaither ve diğ., 2008; Gidman, Hassell, Day ve Payne, 2007) ile birlikte stres düzeylerinin oldukça yüksek olduğu, hata yapma (Gidman, 2007; Cheung, Bouy ve Smet, 2009) olasılıklarının arttığ1 ve dolayısıyla iş performans düzeylerinin de düştüğü (Ercan ve Şar, 2004) bilinmektedir. Çakır Yıldız ve Güneş (2017, s.63) tarafından yapılan çalışmada eczanelerin her ne kadar dışarıdan küçük çaplı işletmeler gibi görünseler de aslında eczanelerin çok büyük bir pazarın öncüleri olduğu yani hem hizmet verilen hasta / müşteri kesimi hem de sunulan hizmetin özelliği sebebiyle çok büyük bir sorumluluğu da beraberinde getirdikleri belirtilmiştir. Dolayısıyla, eczacının ve eczane çalışanının hizmet sunduğu müşteri ve yapılan işin niteliğinin de zorlu olması, ciddi sorumlulukları beraberinde taşımasıyla zaten belirli düzeyde bir stresi de içerdiği söylenebilir. Çünkü, eczanelerde çok düşük bir hata oranının bile çok sayıda hataya (Gaither ve diğ., 2008) ve telafisi zor sonuçlara neden olabileceğinden böyle bir ihtimalin varlığı bile hem eczacı hem de bağlı çalışan üzerinde strese neden olacaktır.

Bu çalışmada, eczacılık mesleğine ilişkin çalışanın stres düzeyi ile iş performansı arasındaki ilişki mevcut literatür çalışmaları üzerinden nitel araştırma yöntemiyle incelenmiştir. Bu bağlamda ScienceDirect, Proquest ve Google Scholar veri tabanları üzerinde literatür taraması yapılmıştır. Çalışmada stres ve iş performansı kavramlarının açıklanmasını müteakiben literatür ta- 
raması ile elde edilen bulgular ortaya konmuştur. Ayrica, elde edilen bulgular ışığında gelecekteki araştırmacılara ve diğer ilgililere yol gösterici nitelikte önerilerde bulunulmuştur.

\section{Stres Kavramı}

Stres tanımına yönelik Oxford sözlügüune bakıldığında (Oxford Learner's Dictionaries, 2020); stres, "birinin hayatındaki sorunlardan kaynaklanan baskı veya endişe şeklinde açıklanan zihinsel baskı, ona zarar verebilecek veya şeklini kaybettirecek bir şeye baskı şeklinde açıklanan fiziksel baskı, bir şeye özel önem verilmesi şeklinde açılanan vurgu ya da zor fiziksel koşulların neden olduğu hastalık şeklinde açiklanmaktadır.

Türkçe Bilim Terimleri Sözlüğünde (Türkçe Bilim Terimleri Sözlüğü, 2013) ise stres; "yapılan işin mahiyetinden, akışından ve çevre koşullarından doğan ve iş sırasında insandan beklenen görevlerin insan üzerinde oluşturduğu baskı" olarak tanımlanmış ve eşanlamlı kelimesinin ise "yüklenme" olduğu belirtilmiştir. Ayrıca Selye (1974) tarafından, stres, bireylerin iş ve performansların yükseltici yöndeyse "olumlu stres", azaltıcı ve hatta hayattan bıkkınlık verici düzeydeyse "olumsuz stres" olarak iki farklı şekilde ele alınmıştır. Çakır Yıldız ve Güneş (2017, s.48) tarafından yapılan çalışmada ise, bireyde tepki yaratan uyarıcılar "stresör" ve bu stresörlere verilen tepki de "stres" olarak tanımlanmıştır.

Kara (2010, s.151) 'nın “İşletme Becerileri Grup Çalışması” isimli kitabında stres nedenleri olarak, zaman baskısı, duygusal sezgiler, durumsal belirsizlik ve etkileşime değinilmiştir.

Güçlü (2001, s.95) tarafından stres belirtileri ile ilgili yapılan çalışmada; fiziksel belirtiler olarak, baş ağrısı, ishal ve kolit, kazalarda artış, düzensiz uyku, sırt ağrıları, çene kasılması veya diş gıcırdatma, hazımsızlık ve ülser, kabızlık, deride döküntü, yüksek tansiyon veya kalp krizi, aşırı terleme, iştahta değişiklik, yorgunluk veya enerji kaybı, kas ağrıları, duygusal belirtiler olarak, kaygı veya endişe, asabilik, depresyon veya çabuk ağlama, saldırganlık veya düşmanlık duygusal olarak tükendiğini hissetme, ruhsal durumun hızlı ve sürekli değişmesi, gerginlik, özgüven azalması veya güvensizlik hissi, aşırı hassasiyet veya kolay kırılabilirlik, öfke patlamaları; zihinsel belirtiler olarak, konsantrasyon, karar verememe veya vermede zorluk, unutkanlık, zihin bulanıklığı, hafızada zayıflık, aşırı olarak hayal kurma, sadece bir 
düşünceyle meşgul olma, mizah anlayışında kayıp, yapılan işten verim alınamama; sosyal belirtiler olarak ise insanlara olan güven problemleri, oluşan problemlerde başkalarını suçlamak, randevulara gitmemek veya çok kısa zaman kala iptal etmek, İnsanların seç ve hatalarını yüzüne vurmak ve onları rencide etmek, çok fazla savunmacı bir tutum sergilemek, bir çok kişi ile küsmek ve küstügü kişiler ile uzun süre konuşmamak olarak gösterilmiştir.

Çakır Yıldız ve Güneş (2017, s.48) tarafından yapılan çalışmada, iş yaşamındaki stresin yapılan işin özelliklerine, çalışılan ortamın koşullarına, bireyin karakterine ve alışkanlıklarına göre şekillendiği, bu nedenle her bireyin sahip olduğu stres toleransının birbirinden farklı olduğu belirtilmiştir Çalgan ve diğerleri $(2009$, s.62) tarafından "iş taleplerinin, bireyin karşılayabileceği düzeyin üzerine çımasının bireyde iş stresine sebep olması" ifadesi de stres toleransının bireylere göre farklılaşacağını göstermektedir.

Klinik eczacılar üzerinde iş stresi ile iş tükenmişliği arasındaki ilişkinin incelendiği, Eslami ve diğerleri (2016, s.21) tarafından yapılan çalışmada; stresin, örgütsel verimsizliğin önemli bir unsuru olduğu, sağlık hizmetlerinin kalitesini ve miktarını azalttı̆̆ı, maliyetlerini büyüttüğ̈̈ ve düşük iş memnuniyetine yol açtı̆̆ belirtilmiştir. Ancak, Çalgan ve diğerleri $(2009$, s.69) tarafından yapılan çalışmada ise stresin bir dereceye kadar iş performansını artıracağı belirtilmiştir.

Bununla birlikte Aktaş (2001) tarafindan stresin genel özellikleri ile ilgili yapılan çalışmada; stresin çok yönlü bir olgu olduğu, olumsuz özelliklerinin yanında olumlu katkılarının da bulunduğu, örgütsel başarıyı ve performansı etkileyebileceği ve çalışanların performansını düşürebileceği gibi aynı zamanda arttırabileceği de belirtilmiştir.

Stres yönetimi müdahaleleri, psikolojik sorunların artmasıyla birlikte 1960'lı yıllarda ortaya çıkmıştır. En geniş tanımıyla, stres yönetimi müdahaleleri, bireylerin stres olaylarıyla başa çıkmalarına ve tetikleyici olaylara bilişsel ve duygusal tepkilerini değiştirerek bu stres faktörlerinden kaynaklanan olumsuz duygular, fizyolojik uyarılma ve / veya sağlık sonuçları ile başa çkmalarına yardımcı olmak için tasarlanmıştır (Kenny, 2005, s.1).

Tutar (2012, s.286) “Örgütsel Davranış” adlı eserinde stresle başa çıkmayı, işletme yönetimi açısından örgütsel ve bireysel başa çıkma yöntemleri olarak iki gruba ayırmıştır. Bu çalışmada, stres yönetiminde bireysel başa çıkma yöntemleri olarak; rahatlama uygulamaları (geliştirici rahatlama yöntemi ile 
derin nefes alma yöntemi), olumlu hayal kurma, egzersiz ve beden hareketleri, davranışsal açıdan kişinin kendini kontrol etmesi, iletişim kurma ile meditasyon, gıda kontrolü ve masaj şeklinde ele alınmıştır. Güçlü (2001, s.103) tarafından yapılan çalışmada ise örgütsel stresin azaltılması için yapılan stratejiler arasında destekleyici örgütsel iklimin oluşturulması, işin zenginleştirilmesi, örgütsel rolün belirlenmesi ve çatışmaların azaltılması, mesleki gelişim yollarının planlanması ve danışmanlık ve işyerinde eğlenceli bir ortamın oluşturulması yer almıştır.

\section{İş Performansı Kavramı}

Dilimize Fransizca "performance" den gelen performans, Türk Dil Kurumu'nda Batı Kökenli Kelimeler Sözlügü̈' ne (Türk Dil Kurumu Sözlükleri, 2019) bakıldığında "Yapılan iş, uygulama, icraat - Herhangi bir olayı veya durumu başarma isteği ve gücü - Kişinin yapabileceği en iyi derece - Herhangi bir eseri, oyunu, işi ve benzerini ortaya koyarken gösterilen başarı" olarak dört farklı şekilde açıklanmıştır. Diğer taraftan, Cambridge sözlüğünde (Cambridge Dictionary, 2020) performans, "bir kişinin, makinenin ve benzerinin bir iş veya etkinliği ne kadar iyi yaptığı", Oxford sözlügüünde (Oxford Learner's Dictionaries, 2020) ise "bir görevin, eylemin gerçekleştirilmesi süreci" şeklinde tanımlanmıştır. Çöl (2008, s.38)'e göre performans, amacın gerçekleştirilme derecesidir. Buna göre performans bir işi yapan bireyin, grubun, çalışma biriminin ya da örgütün o iş aracıllğıyla, hangi hedefe ulaşabildiğini gösterir. Songur (1995, s.1)'e göre ise performans, genel olarak belirli bir amaç için yapılan planlar doğrultusunda ulaşılan noktayı ve diğer bir ifadeyle elde edilenleri kalite ve kantite yönleri ile belirleyen bir kavramdır.

Motowidlo (2003, s.39) iş performansını, "bir bireyin standart bir süre içinde gerçekleştirdiği ayrı davranışsal bölümlerin örgüt için beklenen toplam değeridir" şeklinde tanımlamıştır. Ayrıca, performans öncüllerinin hem bilgi, beceri, motivasyon, alışkanlıklar ve durumsal fırsatlar ve kısıtlamalar gibi doğrudan belirleyicileri hem de yetenek ve kişilikteki bireysel farklılıklar ve bazı durumsal değişkenler dahil dolaylı belirleyicileri içerdiğini belirtmiştir.

Ayrıca, Bozdoğan ve Elibol (2020, s.499-500) tarafından yapılan çalışmada; iş performansının yöneticiler için her zaman önemli bir konu ve önemli bir mihenk taşı olduğu, "örgütün politikaları ve zaman kısıtlamaları dahilinde 
planlanan sonuçların ve görevlerin yerine getirilmesi için çabalayan çalışanların genel performansı" olarak tanımlandığı, çalışan seviyesindeki performansın örgütsel beklentilerle ilişkisi olabileceği ve iş performansını artırmak için çalışanların uygun şekilde motive edilmeleri gerektiği belirtilmiştir.

\section{Konuya Yönelik Literatür Taraması ve Bulgular}

Çalışmanın amacına literatür taraması ile ScienceDirect veri tabanına "stress, job performance" (ScienceDirect, 2020a) yazıldığında 85.025 akademik çalı̧̧maya ulaşılmıştır. Ancak, söz konusu çalışmaların daha dar kapsamda eczacllık mesleği açısından ile ilgili yapılıp yapılmadığını taramak için "stress, job performance, pharmacist" (ScienceDirect, 2020b) yazıldığında ise 1.360 çalı̧̧maya ulaşılmıştır. Ayrıca, uluslararası düzeyde yüksek lisans ve doktora tezlerine ilişkin en geniş veri tabanı kabul edilen ProQuest veri tabanı "stress, job performance" açısından incelendiğinde ise, 521.826 çalışmaya (ProQuest, 2020a) ulaşılmıştır. Stres ile iş performansı ilişkisinin, hemşirelik, polislik, öğretmenlik, satış memurluğu gibi meslekler açısından çok sık araştırma konusu haline geldiği gözlenmiştir. Ancak, eczacılık mesleği açısından daha dar kapsamlı olarak araştırmak için veri tabanına "stress, job performance, pharmacist" yazılarak 19.348 çalışmaya (ProQuest, 2020b) ulaşılmıştır. Google Scholar veri tabanına "stress, job performance" yazıldığında 3.350 .000 çalışmaya (Google Scholar, 2020a); "stress, job performance, pharmacist" yazıld1ğında ise 30.100 çalışmaya (Google Scholar, 2020b) ulaşılmıştır. Buna göre en geniş veri tabanına Google Scholar'ın sahip olduğu söylenebilir. Ancak hem ScienceDirect hem ProQuest hem de Google Scholar veri tabanında bu kadar çok sayıdaki çalışma içerisinde de maalesef çalışanın stresi ile iş performansı arasındaki ilişkiyi eczacı ve eczane çalışanları açısından inceleyen herhangi bir çalışmaya rastlanılmamıştır. Her iki veri tabanındaki çalışmalar genel olarak incelendiğinde ise eczacılık mesleğine yönelik bu çalışmaların genellikle iş tatmini, iş stresi, iş beklentisi, iş kontrolü, iş özellikleri, iş tutumları, performans, verimlilik, motivasyon vb. kavramlarla ilişkili olduğu gözlenmiştir. Dolayısıyla, her ne kadar ayrı ayrı stres ve iş performansı kavramları eczacılık mesleğinde de çok araştırılmış olmasına rağmen, çalışanın stresi ile iş performansını birlikte inceleyen herhangi bir çalışmaya ulaşılamamıştır. Bu bağlamda, literatür taraması sadece eczacılık mesleğindeki stresi ve iş performansını ayrı ayrı incelemiş olsalar bile, erişimin ücretsiz olması sebebiyle 
COVID-19 pandemi sürecinde tercih edilen arama motorlarından olan Google ve Google Scholar veri tabanları aracılığıyla ulaşılan aşağıda verilen çalışmalar üzerinden gerçekleştirilmiştir. Bu bağlamda, literatür taraması kapsamında değerlendirilen makalelerin özellikle özet ve sonuç kısımları incelenerek bu çalışmaya katkısı açısından aşağıda sırası ile sunulmuştur.

Tablo 1. Eczacılık Mesleğinde Stres vel veya İş performansı ile ilgili Çalışmalar

\begin{tabular}{|c|c|c|c|}
\hline $\mathrm{S} / \mathrm{N}$ & Yazar(lar) & $\begin{array}{l}\text { Anahtar } \\
\text { Kelimeler }\end{array}$ & Çalışma Hakkında Özet Bilgi \\
\hline 1 & $\begin{array}{l}\text { Lan } \\
\text { ve } \\
\text { diğerleri } \\
(2020)\end{array}$ & $\begin{array}{l}\text { Eczacı, } \\
\text { Tükenmişlik, } \\
\text { Stres, } \\
\text { İş stresi }\end{array}$ & $\begin{array}{l}\text { Bu çalışmada örgüt iklimi, iş stresi, işyeri tükenmişliği ve } \\
\text { eczacıların işte alıkonması arasındaki ilişki araştırlmıştır. } \\
\text { Çalışmada kesitsel bir tasarım benimsenmiş ve üç eğitim } \\
\text { hastanesinde (bir bölge eğitim hastanesi, bir bölgesel eğitim } \\
\text { hastanesi ve bir tıp merkezi) çalışan eczacılar üzerinde an- } \\
\text { ket çalışması yapılmıştır. Bu çalşmada, hastanelerdeki yö-- } \\
\text { neticilerin güler yüzlü ve sağlıklı bir işyeri yaratabileceği } \\
\text { belirtilmiştir. Ayrıca, örgütsel iklimi nasıl iyileştirebilecek- } \\
\text { lerinin de öğretilebileceği üzerinde durulmuştur. Örgütsel } \\
\text { iklimin daha iyi hale getirilmesiyle, eczacıların iş stresi ve } \\
\text { işyeri tükenmişlik düzeylerinin azaltabileceği, böylece ec- } \\
\text { zane hizmetinin ve ilaç güvenliğinin de kalitesinin artırabi- } \\
\text { leceği ve nihayetinde eczacıların işte kalma niyetinin de ge- } \\
\text { liştirebileceği sonuçlarına ulaşıllıştır. }\end{array}$ \\
\hline 2 & $\begin{array}{l}\text { Teong ve } \\
\text { diğerleri } \\
(2019)\end{array}$ & $\begin{array}{l}\text { Eczacl, } \\
\text { Stres, } \\
\text { İş tatmini }\end{array}$ & 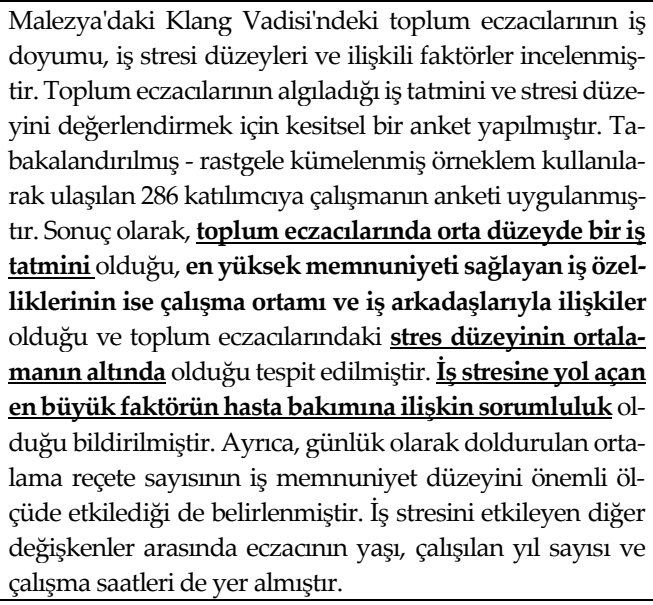 \\
\hline 3 & $\begin{array}{l}\text { Malik ve } \\
\text { diğerleri } \\
\text { (2019) }\end{array}$ & $\begin{array}{l}\text { İş performansı, } \\
\text { Eczacı, } \\
\text { Kişilik } \\
\text { özellikleri }\end{array}$ & $\begin{array}{l}\text { Bu çalışmada iş performansı ile kişilik özellikleri arasındaki } \\
\text { ilişki incelenmiştir. Çalışmada kullanılacak veri setine, } 382 \\
\text { eczacını katılımıla performans ile ilgili raporlama yöne- } \\
\text { ticileri tarafından doldurulması istenen Performans Değer- } \\
\text { lendirme Anketi (PEQ) kullanılarak ulaşılmıstır. Tanımla- } \\
\text { yıcı kesitsel çalış̧a tasarımı kullanılmıştır. Bu çalışmada, }\end{array}$ \\
\hline
\end{tabular}




\begin{tabular}{|c|c|c|c|}
\hline & & & $\begin{array}{l}\text { tüm eczacıların, çalıştıkları alana uygun kişiliklere sahip ol- } \\
\text { madıkları, ellerinden gelenin en iyisini yapamayabilecek- } \\
\text { leri ve sonuçta sağlık sisteminden beklenen rollerini de ye- } \\
\text { rine getiremeyecekleri belirtilmiştir. }\end{array}$ \\
\hline 4 & $\begin{array}{l}\text { Çakır } \\
\text { Yıldız ve } \\
\text { Güneş } \\
(2017)\end{array}$ & $\begin{array}{l}\text { Örgütsel stres, } \\
\text { Örgütsel } \\
\text { sessizlik, } \\
\text { Eczane } \\
\text { çalışanları, } \\
\text { Tükenmişlik }\end{array}$ & $\begin{array}{l}\text { Eczane çalışanları üzerine yapılan bu çalışmada, çalışanla- } \\
\text { rın demografik özellikleri açısından örgütsel stres, sessizlik } \\
\text { ve tükenmişlik düzeyleri arasında anlamlı farklılık görülüp } \\
\text { görülmediği incelenmiştir. Ayrıca, stresin nedenleri ve } \\
\text { oluşturduğu sonuçlar incelenmiştir. Çalışmada örgütsel } \\
\text { sessizlik ve tükenmişlik ile ilgili olan stres kaynakları be- } \\
\text { lirlenmiş, eczane çalışanları üzerindeki stresin iş perfor- } \\
\text { mansını olumsuz yönde etkilediğine dair bulgular tespit } \\
\text { edilmiştir. Yapılan stres ölçeğine ilişkin faktör analizinde } \\
\text { beş faktörün öne çıktığı belirlenmiştir. Bu faktörler “değer } \\
\text { görmeme, tecrübe eksikliği, iş yükü fazlalığı, gelecek } \\
\text { kaygısı, iş yerinde baskı" olarak belirlenmiştir. Yapılan ça- } \\
\text { lışmada cinsiyet, görev ve çalışma süresi açısından örgütsel } \\
\text { stres, örgütsel sessizlik ve tükenmişlik arasında anlamlı } \\
\text { farklılıkların olduğu belirlenmiştir. }\end{array}$ \\
\hline 5 & $\begin{array}{l}\text { Eslami ve } \\
\text { diğerleri } \\
(2016)\end{array}$ & $\begin{array}{l}\text { Klinik eczacl, } \\
\text { Stres, } \\
\text { Tükenmişlik }\end{array}$ & $\begin{array}{l}\text { Bu çalışmada, stresin oluşturduğu olumsuz sonuçların iş } \\
\text { tükenmişliği üzerindeki etkisi araştırılmıştır. Kadın ve er- } \\
\text { kek } 50 \text { kişiden oluşan klinik eczacı üzerinde yapılan çalış- } \\
\text { mada, klinik eczacı stresi ve tükenmişliği arasındaki ilişki } \\
\text { regresyon yöntemi kullanılarak analiz edilmiştir. Sonuçlar } \\
\text { stres ve tükenmişlik arasında güçlü bir ilişki olduğunu gös- } \\
\text { termiştir. }\end{array}$ \\
\hline 6 & Rajan (2014) & $\begin{array}{l}\text { Eczane, } \\
\text { Eczacl, } \\
\text { Stres }\end{array}$ & $\begin{array}{l}\text { Bu çalışma, eczacıların iş stresinin kaynağını belirlemek ve } \\
\text { ayırt etmek, stresin iş tatmini üzerindeki etkisini belirlemek } \\
\text { ve stres ile başa çıkma stratejilerini analiz etmek ve karşılaş- } \\
\text { tırmak amacıyla yapılmıştır. } 60 \text { eczacı üzerinde yapılan ça- } \\
\text { lışmada, analiz edilen stres kaynakları, örgütle ilgili stres } \\
\text { faktörleri ve eczacılara özgü stres faktörleri olmak üzere iki } \\
\text { boyutta incelenmiştir. Çalışmanın sonuçları, stres kaynak- } \\
\text { larının, stres etkisinin ve baş etme stratejilerinin hem özel } \\
\text { hastanelerde hem de özel ecza depolarında çalışan eczacı- } \\
\text { lar tarafından eşit olarak algılandığını göstermiştir. Çalış- } \\
\text { manın hipotezleri test edildiğinde, çalışanların demografik } \\
\text { özellikleri açısından (medeni durum ve eğitim düzeyi) } \\
\text { stres düzeyi ile iş tatmin düzeyi arasında anlamlı bir farklı- } \\
\text { lık olmadığı belirlenmiştir. }\end{array}$ \\
\hline 7 & $\begin{array}{l}\text { Munger } \\
\text { ve diğgerleri } \\
(2013)\end{array}$ & $\begin{array}{l}\text { Eczane, } \\
\text { Eczacl, } \\
\text { Stres }\end{array}$ & $\begin{array}{l}\text { İş kalitesi, sağlık, esneklik, aile ve arkadaşlarla olan ilişkiler, } \\
\text { iş istihdamı gibi faktörlerin göz önüne alınarak bunların } \\
\text { strese neden olup olmadığı araştırılmış ve bu faktörler ara- } \\
\text { sındaki ilişkiler incelenmiştir. Elde edilen bulgulara göre, } \\
\text { katılımcıların, yüksek düzeyde memnuniyetsizlik içeri- } \\
\text { sinde oldukları ve \%50'sinden fazlasının işlerini bırakmayı } \\
\text { düşündükleri belirlenmiştir. Bununla birlikte, katılımcıla- } \\
\text { rın yaklaşık \%20'si tarafından istihdamlarından kaynaklı }\end{array}$ \\
\hline
\end{tabular}




\begin{tabular}{|c|c|c|c|}
\hline & & & $\begin{array}{l}\text { stresin, eczacıların zihinsel sağlı̆̆ını, fiziksel sağlığını, yap- } \\
\text { mış oldukları işin kalitesini ve aile ve arkadaşlarıyla olan } \\
\text { ilişkilerini olumsuz etkilediği belirtilmiştir. }\end{array}$ \\
\hline 8 & $\begin{array}{l}\text { Schafheutle } \\
\text { ve } \\
\text { diğerleri } \\
(2011)\end{array}$ & $\begin{array}{l}\text { Performans, } \\
\text { Eczacl }\end{array}$ & $\begin{array}{l}\text { Eczacılara yönelik yapılan bu çalışmada iş performansının } \\
\text { hangi faktörlere bağlı olduğu ve nelerden etkileneceği araş- } \\
\text { tırılmıştır. Literatür taraması sonucunda, } 37 \text { çalışma ince- } \\
\text { lenmiştir. İnceleme sonucunda belirli özelliklere sahip ec- } \\
\text { zacıların (örneğin, erkek olma, etnik azınlık kökenli olma, } \\
\text { toplum eczanesinde çalışma ve denizaşırı eğitim almış } \\
\text { olma gibi) performans sorunları yaşama olasılığının daha } \\
\text { yüksek olduğu ortaya koymuştur. Çalışmada, bir eczacının } \\
\text { performansının kişisel özellikler, eğitim, işyeri ile ilişkili } \\
\text { faktörler ve zihinsel ve fiziksel sağlık sorunları dahil olmak } \\
\text { üzere birçok faktörden etkilenebileceği belirtilmiştir. Diğer } \\
\text { taraftan, iş yükü ve çalışma ortamıla ilgili faktörler de per- } \\
\text { formans sorunları ile ilişkilendirilmiştir. Ayrıca, literatürde } \\
\text { yer alan çalışmaların incelenmesiyle eczacı performansının } \\
\text { yeterince araştırılmamış bir konu olduğu da belirlenmiştir. } \\
\text { Bununla birlikte, eczacılık mesleğinin ölçülebileceği stan- } \\
\text { dartlar ve temel performans göstergeleri tarafından destek- } \\
\text { lenen (kabul edilebilir) açı bir performans tanımının da } \\
\text { yapılması gerektiği belirtilmiştir. }\end{array}$ \\
\hline 9 & $\begin{array}{l}\text { Gaither ve } \\
\text { diğerleri } \\
(2008)\end{array}$ & $\begin{array}{l}\text { Eczacl, } \\
\text { İş stresi, } \\
\text { Performans }\end{array}$ & $\begin{array}{l}\text { Bu çalışmanın genel amacı, organizasyonel çevrenin özel- } \\
\text { liklerini (kişilerarası etkileşimler, çevresel yönler, ücret ve } \\
\text { terfi durumu, rol stresi ve alternatif işlerin varlığı) inceleyen } \\
\text { doğrudan bir iş stresi modelinin test edilmesi; ekstra rol } \\
\text { faktörleri (iş-ev çatışması); bireysel faktörler (kariyer taah- } \\
\text { hüdü); iş tatmini, örgütsel bağlılık ve işten ayrılma niyeti- } \\
\text { nin işle ilgili psikolojik sonuçlarının araştırılmasıdır. Ame- } \\
\text { rika Birleşik Devletleri'ndeki } 4895 \text { lisanslı eczacının ülke ge- } \\
\text { nelindeki rastgele bir örneğine kesitsel bir posta anketi gön- } \\
\text { derilmiş ve faktör analizleri yapılarak nihai modeli tahmin } \\
\text { etmek için yapısal eşitlik modeli kullanılmıştır. Araştırma } \\
\text { sonucunda, eczane hizmetlerine yönelik artan talep göz } \\
\text { önüne alındığında, sağlık kuruluşlarının pozitif yönlerini } \\
\text { artırıp ve olumsuz çalışma koşullarını düzelterek daha ya- } \\
\text { rarlı sonuçlara ulaşlacağı ortaya konmuştur. Bu bağlamda, } \\
\text { kişilerarası etkileşimlerin geliştirilmesi ile eczacıların mes- } \\
\text { leğe bağlllığının artırılacağı da belirtilmiştir. Diğer taraftan, } \\
\text { işyerinde iş stresinin etkileri konusundaki anlayışın daha } \\
\text { da geliştirilmesi için bu modelleri geliştirmeye devam edil- } \\
\text { mesi gerektiği de vurgulanmıştır. }\end{array}$ \\
\hline 10 & Şar (2005) & $\begin{array}{l}\text { Eczacl, } \\
\text { Eczane, } \\
\text { Stres, } \\
\text { Stresle } \\
\text { başa çıkma }\end{array}$ & $\begin{array}{l}\text { Bu çalışmada, eczane eczacılarında yaşanan stres ile bu } \\
\text { stresin nedenlerinin belirlenmesi ve çözüm önerilerinin } \\
\text { araştırılması amaçlanmıştır. Çalışmada kullanılacak veri } \\
\text { setine, } 83 \text { eczacı ile yapılan yüz yüze anket uygulaması ile } \\
\text { ulaşılmıştır. Sonuçlar değerlendirilerek çözüm önerileri ve } \\
\text { tavsiyeler ile stresle başa çıma yolları ve stresin olumsuz } \\
\text { etkilerinden daha az etkilenmek için yapılması gerekenler } \\
\text { belirlenmiştir. Çalışma sonucunda, eczacıların yaşadığı }\end{array}$ \\
\hline
\end{tabular}




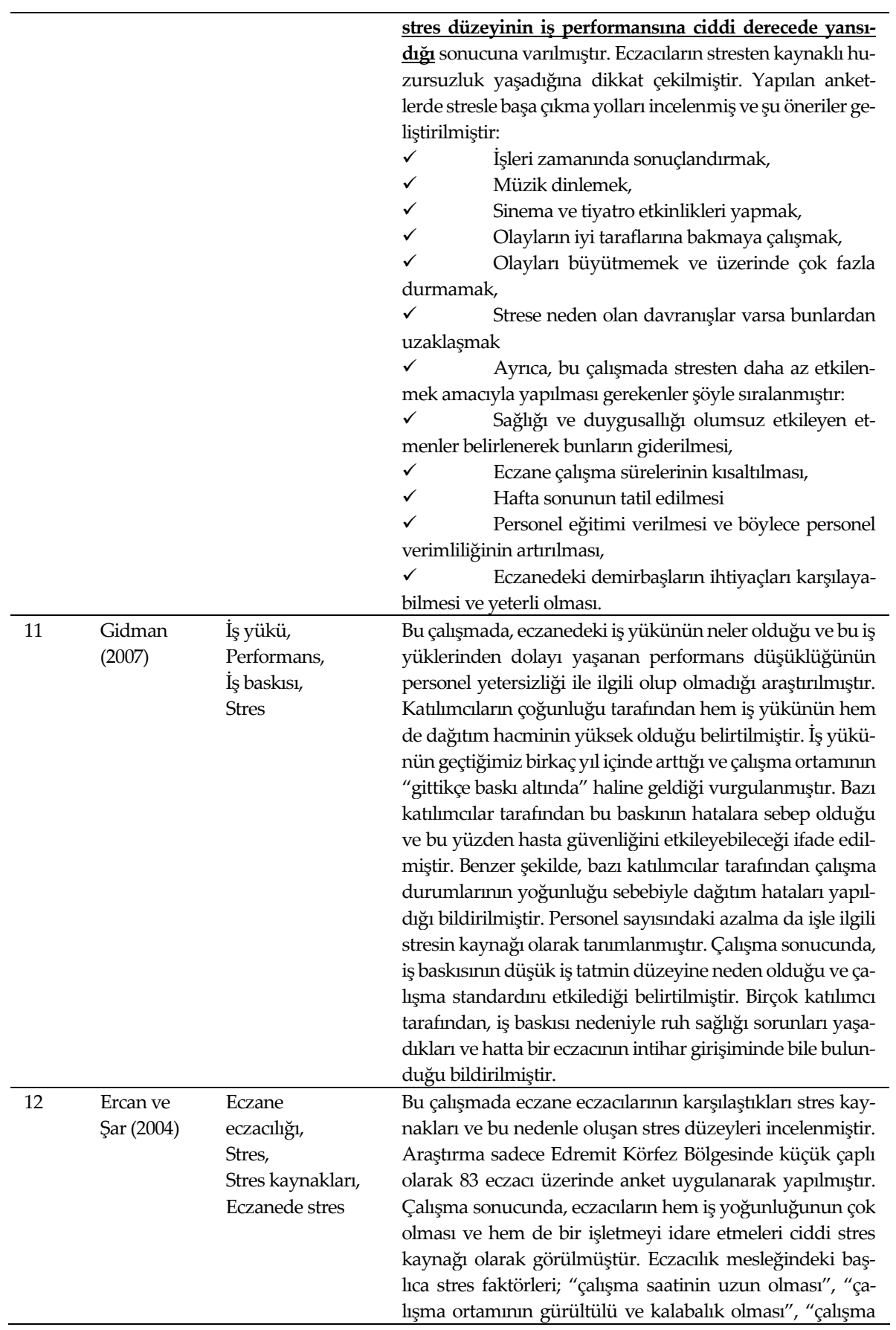




\begin{tabular}{|c|c|c|c|}
\hline & & & $\begin{array}{l}\text { sürecinde dinlenme için uygun bir yerin olmaması" ve "ec- } \\
\text { zanede gereksiz ve rahatsız edici konuşmaların olması" } \\
\text { şeklinde belirlenmiştir. Bu çalışmada, eczane eczacıların- } \\
\text { daki stresin iș performanslarında önemli ölçüde düșük- } \\
\text { lüğe sebep olduğu sonucuna varılmıștır. }\end{array}$ \\
\hline 13 & $\begin{array}{l}\text { Mahrous } \\
\text { (1999) }\end{array}$ & $\begin{array}{l}\text { Stres, } \\
\text { Çalşsan personel, } \\
\text { Hasta talepleri }\end{array}$ & $\begin{array}{l}\text { Bu çalışma, eczanedeki personelin hasta ihtiyaçların karşı- } \\
\text { layıp karşlayamadığının belirlenmesi ve bunun sonu- } \\
\text { cunda oluşan stresin araştırılması amacıyla yapılmıştır. Bir } \\
\text { çalışma ortamındaki trafik yoğunluğu ile tanımlanabilen } \\
\text { bu çalışmada uygulama ortamındaki stres, eczacılara veri- } \\
\text { len talep türlerinin ve sayısının bir sonucu olarak görül- } \\
\text { mektedir. Sonuçta, stres düzeyi çok yükseldiğinde, ilave } \\
\text { personelin gerekli olup olmadığının değerlendirilmesi ge- } \\
\text { rekmektedir. Eczacıların geleneksel bakım hizmetlerinin } \\
\text { yanı sıra hastalar tarafından, hasta bakım hizmetleri sunma } \\
\text { konusundaki artan talepler, eczane ortamlarındaki iş stre- } \\
\text { sini artırma ile sonuçlanmıştır. Buna ek olarak, artan hasta } \\
\text { etkileşimi taleplerinin eczacılar üzerindeki potansiyel etkisi } \\
\text { konusunda çok endişe olsa da ortaya çıkan bu rolün gele- } \\
\text { neksel iş taleplerine göre eczacılar üzerindeki etkisini } \\
\text { doğru bir şekilde tahmin etmek için çok az çalışma yapıl- } \\
\text { mıştır. }\end{array}$ \\
\hline
\end{tabular}

Yukarıdaki tabloda verilen literatür incelendiğinde, genel olarak aşağıdaki bulgulara ulaşılmıştır. Şöyleki;

- Örgütsel iklimin daha iyi hale getirilmesiyle, eczacıların iş stresi ve işyeri tükenmişlik düzeylerinin azaltabileceği, böylece eczane hizmetinin ve ilaç güvenliğinin de kalitesinin artırabileceği ve nihayetinde eczacıların işte kalma niyetinin de geliştirebileceği (Lan ve diğerleri, 2020);

- Toplum eczacılarında en yüksek memnuniyeti sağlayan iş özelliklerinin çalışma ortamı ve iş arkadaşlarıyla ilişkiler olduğu (Teong ve diğ., 2019);

- Günlük olarak doldurulan ortalama reçete sayısının iş memnuniyet düzeyini önemli ölçüde etkilediği (Teong ve diğ., 2019);

- Toplum eczacılarındaki stres düzeyinin ortalamanın altında olduğu (Teong ve diğ., 2019);

- İş stresini etkileyen diğer değişkenlerin en başta hasta bakımına ilişkin sorumluluk olmak üzere, eczacının yaşı, çalışılan yıl sayısı ve çalışma saatlerinin yer aldığı (Teong ve diğ., 2019);

- İş performansı ile kişilik özellikleri arasında ilişki olduğu ve tüm eczaciların, çalıştıkları alana uygun kişiliklere sahip olmadıkları (Malik ve diğ., 2019); 
- Eczane çalışanları üzerindeki stresin iş performansını olumsuz yönde etkilediği (Çakır Yıldız ve Güneş, 2017);

- Eczane çalışanlarındaki stres kaynaklarının "değer görmeme, tecrübe eksikliği, iş yükü fazlalığı, gelecek kaygısı, iş yerinde baskı" şeklinde olduğu (Çakır Yıldız ve Güneş, 2017)

- Eczane çalışanının cinsiyeti, görevi ve çalışma süresi açısından örgütsel stres düzeyleri arasında anlamlı farklılıkların olduğu (Çakır Yıldız ve Güneş, 2017);

- İstihdamdan kaynaklı stresin, eczacıların zihinsel sağlığını, fiziksel sağl1ğını, yapmış oldukları işin kalitesini ve aile ve arkadaşlarıyla olan ilişkilerini olumsuz etkilediği (Munger ve diğerleri, 2013);

- Eczacı performansının yeterince araştırılmamış bir konu olduğu (Schafheutle ve diğ., 2011);

- Belirli özelliklere sahip eczacıların (örneğin, erkek olma, etnik azınlık kökenli olma, toplum eczanesinde çalışma ve denizaşırı eğitim almış olma gibi) performans sorunları yaşama olasılığının daha yüksek olduğu (Schafheutle ve diğ., 2011);

- Bir eczacının performansının kişisel özellikler, eğitim, işyeri ile ilişkili faktörler ve zihinsel ve fiziksel sağlık sorunları dahil olmak üzere birçok faktörden etkilenebileceği (Schafheutle ve diğ., 2011);

- İş yükü ve çalışma ortamıyla ilgili faktörlerin performans sorunları ile ilişkilendirildiği (Schafheutle ve diğ., 2011);

- Eczacilı mesleğinin performans düzeyinin ölçülebileceği standartlar ve temel performans göstergeleri tarafindan desteklenen (kabul edilebilir) açık bir performans tanımının da yapılması gerektiği (Schafheutle ve diğ., 2011);

- Eczane hizmetlerine yönelik artan talep göz önüne alındığında, sağlık kuruluşlarının pozitif yönlerini artırıp ve olumsuz çalışma koşullarını düzelterek daha yararlı sonuçlara ulaşılacağı (Gaither ve diğ., 2008);

- Eczacıların yaşadığı stres düzeyinin iş performansına ciddi derecede yansıdığı (Şar, 2005);

- Eczacılık mesleğindeki iş yükünün geçtiğimiz birkaç yıl içinde arttığı ve çalışma ortamının "gittikçe baskı altında" olduğu (Gidman, 2007);

- Eczacılık mesleğinde iş yükünün oluşturduğu stresin hatalara sebep olduğu ve bu yüzden hasta güvenliğini etkileyebileceği (Gidman, 2007);

- İş baskısının ruhsal sorunlara sebep olduğu (Gidman, 2007); 
- Eczane eczacılarındaki stresin iş performanslarında önemli ölçüde düşüklüğe sebep olduğu (Ercan ve Şar, 2004);

- Eczacllık mesleğindeki başlıca stres faktörleri; "çalışma saatinin uzun olması", "çalışma ortamının gürültülü ve kalabalık olması", "çalışma sürecinde dinlenme için uygun bir yerin olmaması" ve "eczanede gereksiz ve rahatsız edici konuşmaların olması" olduğu (Ercan ve Şar, 2004);

- Eczaciların geleneksel bakım hizmetlerinin yanı sıra hastalar tarafindan, hasta bakım hizmetleri sunma konusundaki artan taleplerin eczane ortamlarındaki iş stresini artırdığı (Mahrous, 1999) bulguları ortaya çıkmıştir.

\section{Tartışma, Sonuç ve Öneriler}

Bu çalışmada, eczacılık mesleğinde çalışanların (eczacı ve eczane çalışanaları) stres düzeyi ile iş performansı arasında ilişki olup olmadığı nitel araştırma yöntemlerinden olan literatür taraması ile incelenmiştir. Literatür taraması sonucunda elde edilen bulgulara göre, eczacılık mesleğinde artan bir iş yükü olduğu ve bu iş yükünün eczacllarda ve eczacıya bağlı çalışanlarda strese sebep olduğu, stresin ise iş hatalarına yola açtığı dolayısıyla çalışanların da iş performansının düş̧üğü söylenebilir. Eczacılık mesleğindeki iş yükünü artış sebebi olarak, Gidman ve diğerleri (2007) tarafından yapılan çalışmada, öncelikle sosyal ve demografik değişiklikler nedeniyle ilaç hizmetlerine olan talep artışı ve sonra eczacıların rol artışı olarak gösterilmiştir. Dolayısıyla, eczacıların ve eczane çalışanlarının stres düzeyi ile iş performans düzeyleri arasında anlamlı ve negatif yönde bir ilişkinin olduğu görülmektedir. Ayrıca, stresin iş tatmini ve iş verimliliği üzerinde de önemli etkileri olduğu söylenebilir. Diğer taraftan, literatürde yer alan çalışmalara göre, eczacının ya da eczane çalışanlarının sahip olduğu kişilik özelliklerinin (Malik ve diğ., 2019; Çalgan ve diğ., 2009; Aktaş, 2001) de stres düzeyi ile ilişkili olabileceği düşünülmektedir.

Sonuç olarak, eczacılık mesleğinde çalışanların yoğun işlerinin stres düzeylerini artırdığı, stres düzeyi arttıkça hata yapma olasılıklarının yükseldiği ve dolayısıyla iş performanslarının da olumsuz yönde etkilendiği belirlenmiştir. Dolayısıyla, çalışanın stresi ile iş performansı arasında olumsuz yönde bir ilişki olduğu söylenebilir. Bu bağlamda, çalışmanın amacına ulaşılmıştır. 
Bununla birlikte, literatür taraması sonucunda; stres düzeyi artan çalışanın sadece iş performansının azaldığı değil aynı zamanda işten zevk alamama, yaptığı işe göre kazancını düşük olarak görme, çalışma saatlerini fazla algılayıp işini bir yük olarak görmeye başlama gibi olumsuz algılara da sahip olabileceği söylenebilir. Bu nedenle, eczacıların ve eczane çalışanlarının iş yükünün aşırıya kaçması halinde stres düzeyi artacağından ve dolayısıyla iş performansı düşeceğinden, iş yükünün azaltılması (Çalgan ve diğ., 2009, s.69) eczacının ya da eczane çalışanının daha başarılı olmasını sağlayacaktır.

Eczacı hem eczane sahibi hem de eczanenin mesul müdür yöneticisi olarak kendi bireysel stresini ve eczanesinde çalışanların stresini iyi yöneterek, iş performansının düşmesi gibi olumsuz sonuçların önüne geçmelidir. $\mathrm{Bu}$ bağlamda eczacılık mesleğinde çalışanlara;

- Tek başına ani kararlar almaktan kaçınması, katılımlı kararlara yönelmesi,

- Problem çözme becerilerinin geliştirilmesi için gerekli hizmet içi eğitimlerin düzenlenmesi ve personele bu anlamda yetki devri yapabilmesi ve böylece insiyatif alabilmelerinin sağlanması,

- Eczanede olası problemin tespit edilmesi, çözüm için seçeneklerin belirlenmesi ve her bir seçeneğin avantaj ve dezavantajlarının eczane çalışanlarıyla birlikte değerlendirilmesi ve birlikte kararsal sonuçların üretilmesi,

- Strese ya da çatışmalara yol açacak sorunların çözümünde gerekirse yakın çevreden destek istenmesi ya da benzer sorunları yaşayanların tecrübelerinden yararlanılması,

- Olaylara bakış açısının değiştirilmesi, eczacının kendisini veya çalışanlarını suçlaması yerine anlamaya veya anlaşılmaya çalışılması,

- Bununla birlikte, özellikle COVID-19 pandemisi gibi kriz durumlarında çalışma saatlerinin gözden geçirilmesi gerekirse esnek çalışma saatlerinin getirilmesi ya da dönüşümlü çalışma programının oluşturulması,

- Reçete hatalarını azaltmak için reçete kontrolleri üzerinde yoğunlaşılması ve yönetim hatalarının önlenmesi için hastalarla yeterince iletişim kurulmasi,

- Ayrıca, çözümü zor görünen probleme odaklanmaya ara verilmesi, gevşeme, yürüyüş yapma, müzik dinleme ya da bir arkadaşı ile güzel bir zaman geçirme gibi stres düzeyinin azalmasına iyi gelecek bir aktiviteye zaman ayrılması önerilmiştir. 
Nihayetinde, eczacılık mesleğinde zamanın iyi yönetilmesi durumunda işlerin zamanında yetişeceği ve iş yükünün oluşturduğu stres seviyesinin de azalacağı söylenebilir. Bu bağlamda, eczacı ve eczane çalışanları için zor ve sevimsiz görünen işlere günün ilk saatlerinde yer verilmesi, günün diğer saatlerinde daha az stres ile iş yapılmasını sağlayabilir. Böylece hem eczacının hem de eczane çalışanın iş performans düzeyi artabilir ve talep edilen iş sonuçlarının da başarı düzeyi yükselebilir.

Bu çalışmanın kısıtları bulunmaktadır, eczacilık mesleğinde çalışanın stresi ile iş performansı arasındaki ilişkinin sadece literatür taramasıyla değil, aynı zamanda ampirik çalışmalar ile desteklenmesi elde edilecek sonuçları bilimsel açıdan daha güçlü kılacaktır. Ancak, bu çalışmanın literatür taraması COVID-19 küresel pandemisinin yaşandığı dönemde (zorunlu ve geçici karantina ya da izolasyon sebebiyle) yapılması nedeniyle ampirik çalışma yapılamamıştır. Bu nedenle, konuya yönelik gelecekteki çalışmaların ampirik nitelikte olması konunun daha belirgin bir şekilde aydınlığa kavuşmasını sağlayacaktır.

Ayrıca, gelecekteki araştırmacılara, eczacılık mesleğinde strese yol açan hata yapma olasılığının baskısına yönelik, Cheung ve diğerleri (2009) tarafından da önerildiği üzere, ülkemiz gibi orta ve düşük gelirli ülkelerdeki eczacllık mesleğindeki ilaç dağıtım hatalarının ve altında yatan nedenlerin derinlemesine analiz edilerek ortaya konması ve bu alanda daha kapsamlı ve ampirik nitelikteki çalışmaların yapılması önerilebilir. 


\title{
EXTENDED ABSTRACT
}

\section{Is There A Relationship Between the Employee's Stress Level and Job Performance? A Literature Scan- ning for the Pharmaceutical Profession}

\author{
Gülşen Kırpık - Mehmet Ali Doğan \\ Adryaman University
}

Today's very complex, uncertain and variable structure causes stress and tension due to pressure and tension on pharmacists and pharmacy workers as on all individuals. It can be said that the level of stress experienced with the COVID-19 pandemic, which we live on a global level and when we do not know when and how to solve it, is even higher. However, due to the individual characteristics and demographic characteristics of the employees, or differences from the culture in which they live, some of the employees in the same workplace may be less affected by similar conditions, while others may be more positive or negative.

Increasing workload of pharmacists and pharmacists, who are the owner of the pharmacies and also the manager as responsible manager (Çakır Yıldız and Güneş, 2017; Schafheutle, Seston and Hassell, 2011; Gaither et al., 2008; Gidman, Hassell, Day and Payne, 2007), it is known that their stress levels are quite high, their probability of making mistakes (Gidman, 2007; Cheung, Bouy and Smet, 2009) increases and thus their job performance levels decrease (Ercan and Şar, 2004). In the study conducted by Çakır Yıldız and Güneş (2017, p.63), although pharmacies may seem like small-scale businesses from the outside, in fact, pharmacies are a huge market due to the fact that they are the pioneers of a very large market; It was stated that they brought the responsibility. Therefore, it can be said that the quality of the customer and the work done by the pharmacist and the pharmacy worker are difficult, and they carry serious responsibilities and they also contain a certain level of stress. Because even the very low error rate in pharmacies can cause many errors (Gaither et al., 2008) and difficult to compensate, even the existence of such a possibility will cause stress on both the pharmacist and the employee. 
In this study, the relationship between the stress level and job performance of the employee related to the pharmacy profession has been investigated through qualitative research method over the existing literature studies. In this context, a literature review was conducted on ScienceDirect, ProQuest and Google Scholar databases. Following the explanation of the concepts of stress and job performance in the study, the findings obtained through the literature review were revealed.

Although there are many studies that examine the relationship between employee stress and job performance in the ScienceDirect, ProQuest and Google Scholar database for the purpose of the study, no studies investigating this relationship in terms of pharmacists and pharmacy workers have been encountered. When the studies in both databases are analyzed in general, these studies related to the pharmacy profession generally include job satisfaction, job stress, job expectation, job control, job characteristics, job attitudes, performance, efficiency, motivation, etc. It is observed that it is related with concepts. Therefore, although the concepts of stress and job performance were investigated separately in the pharmaceutical profession, no studies examining the stress and job performance of the employee at the same time could be reached. In this context, the literature review was carried out through studies accessed through Google and Google Scholar databases, which are among the preferred search engines in the COVID-19 pandemic process, even though they have studied the stress and job performance in the pharmaceutical profession separately.

When the literature on the subject of the study is analyzed, the following findings have been reached in general. Namely;

- By improving the organizational climate, pharmacists can reduce their job stress and workplace burnout levels, thereby improving the quality of pharmacy service and drug safety, and ultimately improving the intention of pharmacists to remain at work (Lan et al. 2020);

- The job characteristics that provide the highest satisfaction in community pharmacists are the working environment and relationships with colleagues (Teong et al., 2019);

- The average number of prescriptions filled daily affects job satisfaction significantly (Teong et al., 2019);

- The stress level in community pharmacists is below average (Teong et al., 2019); 
- Other variables that affect work stress include the age of the pharmacist, the number of years worked, and the working hours, primarily the responsibility for patient care (Teong et al., 2019);

- There is a relationship between job performance and personality traits and all pharmacists do not have personalities appropriate for their field of work (Malik et al., 2019);

- Stress on pharmacy employees negatively affects job performance (Çakır Yıldız and Güneş, 2017);

- Stress sources in pharmacy employees are "lack of value, lack of experience, excessive workload, future anxiety, pressure at work" (Çakır Yıldız and Güneş, 2017)

- There are significant differences between organizational stress levels in terms of gender, duty and working time of the pharmacy worker (Çakır Yıldız and Güneş, 2017);

- Stress from employment negatively affects pharmacists' mental health, physical health, the quality of their work and their relationships with family and friends (Munger et al., 2013);

- Pharmacist performance is an under-studied topic (Schafheutle et al., 2011);

- Pharmacists with certain characteristics (such as being male, ethnic minority origin, working in a community pharmacy, and having overseas education) are more likely to experience performance problems (Schafheutle et al., 2011);

- The performance of a pharmacist can be affected by many factors, including personal characteristics, education, workplace related factors, and mental and physical health issues (Schafheutle et al., 2011);

- Factors related to workload and work environment are associated with performance problems (Schafheutle et al., 2011);

- A clear performance definition (Schafheutle et al., 2011), which is supported by standards and basic performance indicators, in which the performance level of the pharmaceutical profession can be measured, should also be made;

- Given the increasing demand for pharmacy services, more beneficial results will be achieved by increasing the positive aspects of healthcare institutions and improving the negative working conditions (Gaither et al., 2008); 
- The level of stress experienced by pharmacists is reflected in job performance seriously (Şar, 2005);

- The workload in the pharmaceutical profession has increased over the past few years and the working environment is "increasingly under pressure" (Gidman, 2007);

- The stress caused by the workload in the pharmacy profession causes errors and therefore may affect patient safety (Gidman, 2007);

- Work pressure causes mental problems (Gidman, 2007);

- Stress in pharmacy pharmacists caused a significant decrease in job performance (Ercan and Şar, 2004);

- Major stress factors in the pharmacy profession; "Long working hours", "noisy and crowded working environment", "no suitable place for rest during the working process" and "unnecessary and disturbing speeches in the pharmacy" (Ercan and Şar, 2004);

- Aside from the traditional care services of pharmacists, it has been revealed that the increasing demands of patients to provide patient care services increase work stress in pharmacy settings (Mahrous, 1999).

When the results of the study are evaluated together, it can be said that there is a significant and negative relationship between the stress level and job performance levels of pharmacists and pharmacy workers. In addition, stress has been shown to have significant effects on job satisfaction and job efficiency. On the other hand, according to the studies in the literature, it is thought that the personality traits of the pharmacist or pharmacy employees (Malik et al., 2019; Çalgan et al., 2009; Aktaş, 2001) may also be related to the level of stress.

The pharmacist, as both the owner of the pharmacy and as the responsible manager of the pharmacy, should manage his / her own personal stress and the stress of the employees working in his / her pharmacy, and prevent negative consequences such as decreased job performance. In this context, the following suggestions have been proposed to those working in the pharmaceutical profession:

- Avoiding making sudden decisions only, turning towards participatory decisions,

- Organizing the in-service trainings necessary for the development of problem solving skills and enabling the personnel to transfer authority in this sense and thus take initiative, 
- Determining possible problems in the pharmacy, determining the options for the solution, evaluating the advantages and disadvantages of each option together with the employees of the pharmacy and producing decisive results together,

- In the solution of problems that may lead to stress or conflict, if necessary, support from the immediate environment or benefit from the experiences of those who have similar problems,

- Changing the perspective of the events, trying to understand or be understood instead of accusing the pharmacist of himself or his employees,

- However, especially in crisis situations such as the COVID-19 pandemic, if working hours need to be revised, bringing flexible working hours or creating a rotating work schedule,

- Adequate communication with patients to focus on prescription controls to prevent prescription errors and prevent management errors,

- It was also suggested that time should be taken for an activity that would be good for reducing stress levels, such as taking a break from focusing on the problem that seems difficult to resolve, relaxation, walking, listening to music or having a good time with a frien

In the end, it can be said that if the time is managed well in the pharmaceutical profession, the work will grow on time and the stress level caused by the workload will decrease. In this context, placing the jobs that seem difficult and unattractive for pharmacists and pharmacy workers in the first hours of the day may provide less stress at other times of the day. Thus, both the pharmacist's and pharmacy employees' job performance level can be increased and the success level of the demanded business results can be increased.

\section{Kaynakça / References}

Aktaş, A. (2001). Bir kamu kuruluşunun üst düzey yöneticilerinin iş stresi ve kişilik özellikleri. Ankara Üniversitesi SBF Dergisi, 56(4). DOI: 10.1501/SBFder_0000001872

Bozdoğan, S. C. ve Elibol, G. (2020). The effect of leader member exchange on organizational support, job satisfaction and job performance. Current Researches in Economics and Administrative Sciences. Ed. Y. Akay ve İ. Serbestoğlu, $1^{\text {st }}$ Ed., Ivpe Cetinje: Montenegro, 496-513. 
Cambridge Dictionary (2020). 11.06.2020 tarihinde https://ditinary.cambridge.org/dictionary/english/performance adresinden erişildi.

Cheung, K. C., Bouvy, M. L. ve Smet, P. A. G. M. D. (2009). Medication errors: the importance of safe dispensing. Br J Clin Pharmacol. 67(6), 676-680. doi: 10.1111/j.1365-2125.2009.03428.x

Çakır Yıldız, N. ve Güneş, M. Ş. (2017). Örgütsel stresin, örgütsel sessizlik ve tükenmişlik üzerine etkisi: Eczane çalışanları üzerinde bir araştırma. Uygulamalı Sosyal Bilimler Dergisi, 1(1), 45-66.

Çalgan, Z., Yeğenoğlu, S. ve Aslan, D. (2009). eczacilarda mesleki bir sağlık sorunu: tükenmişlik. Hacettepe Üniversitesi Eczacılık Fakültesi Dergisi, 29(1), 61-74.

Çöl, G. (2008). Algılanan güçlendirmenin işgören performansı üzerine etkileri. Doğuş Üniversitesi Dergisi, 9 (1), 35-40.

Ercan, A. ve Şar, S. (2004). Edremit Körfez bölgesindeki eczane eczacilarının stres kaynakları. Ankara Eczacılık Fakültesi Dergisi, 33 (4), 217-242.

Eslami, A., Kouti, L., Javadi, M.-R., Assarian, M., ve Eslami, K. (2016). An investigation of job stress and job burnout in iranian clinical pharmacist. Journal of Pharmaceutical Care, 3(1-2), 21-25. Retrieved from http://jpc.tums.ac.ir/index.php/jpc/article/view/91

Güçlü N. (2001). Stres yönetimi. G.Ü. Gazi Ĕ̆itim Fakültesi Dergisi, 21(1), 91-109.

Gaither, C. A, Kahaleh, A. A, Doucette, W. R, Mott, D. A, Pederson, C. A, ve Schommer, J. C. (2008). A modified model of pharmacists' job stress: the role of organizational, extra-role, and individual factors on work-related outcomes. Res Social Adm Pharm, 4(3), 231-243. doi:10.1016/j.sapharm.2008.04.001

Gidman, W. K., Hassell, K., Day, J. ve Payne, K. (2007). The impact of increasing workloads and role expansion on female community pharmacists in the United Kingdom. Res Social Adm Pharm, 3(3), 285-302. doi: 10.1016/j.sapharm.2006.10.003.

$\begin{array}{llll}\text { Google Scholar } \quad \text { (2020a). } & 12.06 .2020 & \text { tarihinde }\end{array}$ https://scholar.google.com.tr/scholar?hl=tr\&as_sdt=0\%2C5\&q=stress $\% 2 \mathrm{C}+\mathrm{j}$ $\mathrm{ob}+$ performance\&btnG $=$ adresinden erişildi.

$\begin{array}{llll}\text { Google } \quad \text { Scholar } & \text { (2020b). } & 12.06 .2020 & \text { tarihinde }\end{array}$ https://scholar.google.com.tr/scholar?hl=tr\&as_sdt=0\%2C5\&q=stress $\% 2 \mathrm{C}+\mathrm{j}$ ob+performance $\% 2 \mathrm{C}+$ pharmacist\&btnG $=$ adresinden erişildi.

Kara, M. A. (2010). İşletme becerileri grup çalışması. Murathan Yayınevi: Trabzon.

Kenny, D. T. (2005). Stress management. Cambridge Handbook of Psychology, Health and Medicine (2nd Ed.). Cambridge: Cambridge University Press. 
Lan. Y-L., Huang, W-T., Koa, C-L., Wang, H-J. (2019). The relationship between organizational climate, job stress, workplace burnout, and retention of pharmacists. Journal of Occupational Health, 62(2) , 1-9. DOI: 10.1002/13489585.12079

Mahrous, H. (1999). The use of queuing theory and computerized queuing model to analyze, predict, and modify traffic intensity in a given retail pharmacy practice environment. eLIBRARY ID: 6674509, ISBN: 0591976641 https://www.elibrary.ru/item.asp?id=6674509 adresinden erişilmiştir.

Malik, M., Qureshi, A. ve Hussain, A. (2019). Personality and job performance of pharmacists: are we ready for adopting pharmacy practice change in Pakistan? International Journal of Current Research, 11(1), 60-63 DOI: https://doi.org/10.24941/ijcr.33842.01.2019

Motowidlo, S. J. (2013). Job performance. In W. C. Borman, D. R. Ilgen, \& R. J. Klimoski (Eds.), Handbook of psychology: Industrial and organizational psychology, Vol. 12 (p.39-53). John Wiley \& Sons Inc. https://doi.org/10.1002/0471264385.wei1203

Munger, M. A., Gordon, E., Hartman, J., Vincent, K. and Feehan, M. (2013). Community pharmacists' occupational satisfaction and stress: A profession in jeopardy? Journal of the American Pharmacists Association, 53(3), Pages 282-296. https://doi.org/10.1331//APhA.2013.12158

Oxford Learner's Dictionaries (2020). 11.06.2020 tarihinde https://www.oxfordlearnersdictionaries.com adresinden erişildi.

ProQuest (2020a). 12.06.2020 tarihinde https://search.proquest.com/pqdtglobal/results/E82FDB65D3E6440APQ/1?accountid=15329 adresinden erişildi.

ProQuest (2020b). 12.06.2020 tarihinde https://search.proquest.com/pqdtglobal/results/BA74163513374B84PQ/1?accountid=15329 adresinden erişildi

Rajan, D. (2014). Work stress among pharmacists: A comparative analysis. Global Management Review, 8(2), 1-18.

Schafheutle, E. I., Seston, E. M. ve Hassell, K. (2011). Factors influencing pharmacist performance: A review of the peer-reviewed literature. Healt Policy, 102 (23), 178-192. doi: 10.1016/j.healthpol.2011.06.004.

ScienceDirect (2020a). 12.06.2020 tarihinde https://www.sciencedirect.com/search?qs=stres $\% 2 \mathrm{C} \% 20$ performance adresinden erişildi.

ScienceDirect (2020b). 12.06.2020 tarihinde https://www.sciencedirect.com/search?qs=stress $\% 2 \mathrm{C} \% 20$ job $\% 20$ performance $\% 2 \mathrm{C} \% 20$ pharmacist adresinden erişildi.

Selye H. (1974). Stress without dissress, New York; J.B.Lippencott Comp, 26-39. 
Songur, H. M. (1995). Mahalli idarelerde performans ölçümü. Mahalli İdareler Genel Müdürlüğü Yayını: No:6, Ankara.

Şar, S. (2005). Edremit Körfez bölgesindeki eczane eczacılarının stresle başa çıkma yöntemleri. Ankara Eczacılık Fakültesi Dergisi, 34 (2), 107-118.

Tutar, H. (2012). Örgütsel davranış. Detay Yayıncilı: Ankara

Türk Dil Kurumu Sözlükleri (2019). 12.06.2020 tarihinde https://sozluk.gov.tr/ adresinden erişildi.

Türkçe Bilim Terimleri Sözlüğü (2013). 11.06.2020 tarihinde http://www.tubaterim.gov.tr/ adresinden erişildi.

Teong, W. W., Ng, Y. K., Paraidathathu, T. ve Chong, W. W. (2019). Job satisfaction and stress levels among community pharmacists in Malaysia. Journal of Pharmacy Practice and Research, 49(1), Pages 9-17. https://doi.org/10.1002/jppr.1444

\section{Kaynakça Bilgisi / Citation Information}

Kırpık, G. ve Doğan, M. A. (2020). Çalışanın stres düzeyi ile iş performansı arasında bir ilişki var mı? Eczacılık mesleğine yönelik bir literatür taraması. OPUS-Uluslararası Toplum Araştırmaları Dergisi, 16(27), 720-743. DOI: 10.26466/opus.753945 